\title{
Body Mass Bias in Exercise Physiology
}

\author{
Paul M. Vanderburgh \\ University of Dayton, Dayton, $\mathrm{OH}$
}

USA

\section{Introduction}

Body mass bias in the field of exercise physiology has been the subject of increased focus over the past twenty years. This is based primarily on the fact that key widely held assumptions about the relationships between body mass and human performance have been challenged by theory and empirical data. The result for how we express certain variables of physical fitness has been generally two-fold: a systematic and meaningful body mass bias against larger, not fatter, individuals and spurious attribution of the effect of body mass on key dependent variables.

Physical educators, the military services, law enforcement agencies, and conditioning coaches have readily used fitness tests comprised of events that involve body mass as the primary resistance. Common tests include pushups, situps, and timed distance runs. Virtually none of these tests takes into account one's body mass in scoring because a common assumption has been that larger people have more muscle to move the heavier mass. In short, these factors are assumed to "wash out" any body mass bias. Empirical research has shown, however, that these types of tests impose a substantial and predictable bias against larger, not just fatter, body mass (Crowder \& Yunker, 1996; Harman \& Frykman, 1992; Jaric et al., 2005; Markovic \& Jaric, 2004; Vanderburgh et al., 1995). Similarly, because maximal oxygen consumption $\left(\mathrm{VO}_{2 \max }\right.$ in $\left.\mathrm{L} / \mathrm{min}\right)$ and maximal strength increase with body mass, a common convention to compare individuals is to divide $\mathrm{VO}_{2 \max }$ or strength measures by body mass. Expressing these human performance indices as simple ratios this way has been scrutinized given that the numerator does not change at the same rate as the denominator (Astrand \& Rodahl, 1986; Heil, 1997). Again, the result is not only a body mass bias against larger individuals but, in the case of inferential research, improper accounting for the effects of body mass on outcome variables.

In certain physically demanding occupations, especially the military, body mass bias has substantive implications. Work physiologists have determined that despite body mass bias in the common military physical fitness tests, the larger service members were often better performers of the physically demanding occupational tasks (Bilzon et al., 2002; Lyons et al., 2005; Rayson et al., 2000). That is, they could carry more, more easily evacuate casualties, and better engage in heavy materiel handling. Yet, the smaller personnel were achieving better scores on the physical fitness tests, the results of which have significant promotion and advancement implications (Vanderburgh \& Mahar, 1995; Crowder \& Yunker, 1996).

This chapter chronicles the fundamentals and applications of body mass bias in fitness and exercise physiology, to include the theory and empirical data used to evaluate it. It also 
explains the real world implications of body mass bias in the military services, and how to mitigate its undesirable or unintended effects.

\section{Body mass bias and biological scaling}

Body mass bias is simply the notion that larger individuals have an unfair advantage over smaller, or vice-versa, in measures of exercise performance. It is more formally defined as the correlation between a raw score (e.g., maximal weight lifted, pushups repetitions, oxygen uptake) and body mass. A non-zero correlation indicates the presence of bias; a correlation not different from zero indicates the absence of such bias. Some biases are rather intuitive. Maximal grip strength, bench press or absolute work rate on a cycle ergometer are measures that would give larger individuals an advantage since each is largely dependent on muscle yet body mass is not the source of the resistance. As a result, a sport like powerlifting employs body weight classes and maximal power is often expressed relative to body mass. Less intuitive, perhaps, are measures that advantage smaller individuals. These include those that measure the capacity to move one's body mass in exercises such as pushups or distance running. The less-than-intuitive quality is based on the common assumption that larger individuals have more muscle to move body mass so there should be no particular advantage to the smaller. A closer look, however, at laws of biological scaling and their application to military physical fitness data make a compelling case that the common fitness test events of pushups, situps and distance running, and even $\mathrm{VO}_{2 \max }$ expressed per unit of body mass, impose a bias against larger, not just fatter, personnel (Vanderburgh, 2007, 2008).

Perhaps an easy way to think of this is through the analogy of a $2 \times 2 \times 4$ solid rectangular block (Fig. 1) of constant density. Its cross-sectional area (CSA) would be $2 \times 2$ or $4 \mathrm{sq} f \mathrm{ft}$ and, with a density of 1.0, its weight would be $16 \mathrm{lbs}$. Imagine that the block (PRE) turned into an identical scale-model block of the same density, but with sides $25 \%$, or 1.25 times longer (the POST block). Simple geometric principles dictate, then, that CSA would be $2.5 \times 2.5$, or 5.25 sq $\mathrm{ft}$. This represents a $56.25 \%$ increase in CSA. Similarly, the new weight of $31.25 \mathrm{lbs}(2.5 \mathrm{x}$ $2.5 \times 5=31.25 \mathrm{lbs}$ ) is a $95.3 \%$ increase.
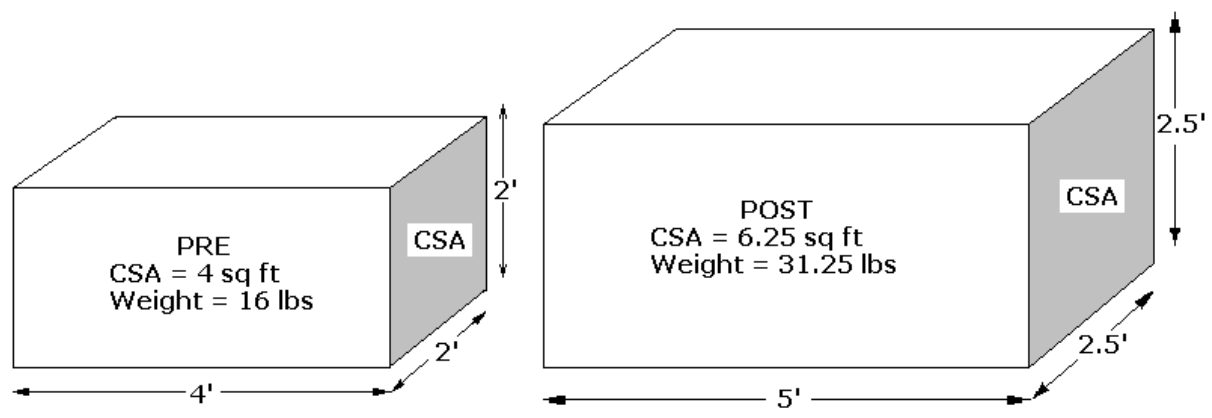

Fig. 1. Comparison of change in length, cross-sectional area (CSA) and weight

Scaling theory helps us understand why these dimensions change at different rates and biological scaling principles elucidate the relevance to human performance. As shown in 
Table 1, if length increases by 1.25 (a 25\% change), then CSA changes by 1.252 and weight changes by $1.25^{3}$. This is because length is considered a one-dimensional variable, area is two-dimensional, and weight (just like volume) is three-dimensional. In terms of biological significance, one can think of the human body just like the block in the present example. It has its own body mass and its CSA is considered to be muscle cross sectional area, one of the prime determinants of strength. Therefore, the $95 \%$ increase in weight shown in Table 1 is accompanied by only a $56.25 \%$ increase in strength. This human performance scaling concept is critically important because it challenges the common assumption that an $\mathrm{X} \%$ larger person should be $\mathrm{X} \%$ stronger. Empirical evidence supports the fallacy of this assumption. Also of critical importance is the notion that "larger" assumes an exact scale model, not larger because he/she is fatter or taller.

\begin{tabular}{|c|c|c|c|c|}
\cline { 2 - 5 } \multicolumn{1}{c|}{} & PRE & POST & Multiplier / \% Increase & Calculation \\
\hline Length & $4^{\prime}$ & $5^{\prime}$ & $1.25 / 25 \%$ & $(1.25)^{1}=1.25$ \\
\hline CSA & $4 \mathrm{ft}^{2}$ & $6.25 \mathrm{ft}^{2}$ & $1.5625 / 56.25 \%$ & $(1.25)^{2}=1.5625$ \\
\hline Weight & $16 \mathrm{lbs}$ & $31.25 \mathrm{lbs}$ & $1.9531 / 95.31 \%$ & $(1.25)^{3=1.9531}$ \\
\hline
\end{tabular}

Table 1. Calculations of Fig. 1 changes in dimensions due to scale model increase in size

\section{Allometric scaling in fitness tests}

Allometry, a term often associated with biological scaling, is the relationship between the size of an organism and the size of any of its parts, such as muscle or blood vessel CSA, limb length, eyeball radius, etc. Allometry provides the theoretical bases upon which empirical findings can be compared. In the case of Fig. 1 and its analogous application to the human body, strength $(\mathrm{S})$ does not change proportionally to body mass (M). If it did, it would also increase by $95.3 \%$. Instead, its $56.25 \%$ increase can be explained by the allometric relationship:

$$
\mathrm{S} \text { a } \mathrm{M}^{2 / 3}
$$

This is derived from the fact that weight is a three-dimensional and CSA a two-dimensional variable (Astrand \& Rodahl, 1986; Jaric, 2002). From Eq. 1 we can substitute the delta, or change on both sides such that:

$$
\Delta S \text { a } \Delta \mathrm{M}^{2 / 3}
$$

Indeed, 1.5625 (the change in CSA, or strength) $=1.95312 / 3$ (the change in mass). This exponent of $2 / 3$, often called an allometric exponent, tells us that the proper way to express muscle strength to allow for comparisons between individuals of different body mass is: $\mathrm{S} / \mathrm{M}^{2 / 3}$. This is because both sides change at the same rate - a necessary condition for expressing ratios in physiology (Astrand \& Rodahl, 1986; Vanderburgh, 1998). Though unconventional, this index should show zero correlation with body mass in a large sample of subjects. It is also very useful in understanding how other variables, such as fitness test scores, or maximal oxygen uptake, change with body size changes.

Since blood vessel CSA is also a two-dimensional variable, and oxygen delivery is associated with blood flow, then maximal oxygen uptake, $\mathrm{VO}_{2 \max }$, would be subject to a similar relationship:

$$
\mathrm{VO}_{2 \max } \text { a } \Delta \mathrm{M}^{2 / 3}
$$


and the following index: $\mathrm{VO}_{2 \max } / \mathrm{M}^{2 / 3}$. Once again, this is an unconventional index but allows for comparisons of maximal aerobic capacity between individuals of different body mass such that body mass bias is zero. This index has been validated this index in a large sample of 230 women and 210 men (Heil, 1997).

The effects of body mass changes on strength and $\mathrm{VO}_{2 \max }$ can be used to derive appropriate scaling indices for events like distance runs (DR) and maximal pushups (PU) or situps (SU) repetitions. One explanation (Jaric et al., 2002b) for its derivation is that the ability to move one's body mass is directly proportional to strength (which is directly proportional to $\mathrm{M}^{2 / 3}$ ) and indirectly proportional to body mass $\left(\mathrm{M}^{1}\right)$. Therefore, since PU or SU a M $\mathrm{M}^{2 / 3} / \mathrm{M}^{1}$, then:

PU or SU a $\mathrm{M}^{-1 / 3}$

Interestingly, the ratio scaling that results, $\mathrm{PU} / \mathrm{M}^{-1 / 3}$, is equivalent to $\mathrm{PU} \cdot \mathrm{M}^{1 / 3}$ (same for $\mathrm{SU}$ ). For the distance run (DR), the scaling index is derived as follows (Vanderburgh \& Mahar, Vanderburgh \& Crowder, 2006; Vanderburgh \& Laubach, 2007): Since distance run time is indirectly proportional to $\mathrm{VO}_{2 \max }$, expressed per unit of body mass (Nevill et al., 1992), and $\mathrm{VO}_{2 \max }$ in $\mathrm{L} / \mathrm{min}$ ( i.e., no adjustment for body mass) is directly proportional to $\mathrm{M}^{2 / 3}$ (Eq. 3), then DR a $\mathrm{M}^{1} / \mathrm{M}^{2} / 3$, or

\section{$\mathrm{DR}$ a $\mathrm{M}^{1 / 3}$}

This means that DR time goes up as M goes up. Since low score wins in run time, the DR expression would be $\mathrm{DR} / \mathrm{M}^{1 / 3}$. This index has been empirically validated as well (Crecilius et al., 2008; Crowder \& Yunker, 1996; Vanderburgh et al., in press).

\section{Empirical validation of allometric modeling in fitness tests}

"Empirically validated" in these cases indicates that researchers have tested the hypotheses of Eqns. 1,3-5 in reasonably large samples to determine the actual body mass exponent and compared it with the theoretical. For purposes of illustration, this can be done using real data from the sport of competitive powerlifting and the methods described in more detail by Vanderburgh (1998). Powerlifting, comprised of maximal one-repetition lifts in the squat (SQ), bench press (BP), deadlift (DL), and total (TOT) of all three, is a good choice for examining body mass exponents for several reasons. First, it is a sport of primarily muscular strength, not power, hand-eye coordination, or even complex cognition, all of which could be confounders in examining the relationship between performance and body mass. Second, at the elite level (not counting the super heavyweight division, which has no weight limit), all competitors are very lean, thus eliminating body fat as a confounder. Third, the two primary determinants of performance are strength and body mass. Therefore, a sample of powerlifting world record holders would be heterogeneous in body mass and weight lifted - almost nothing else.

The determination of the empirical exponent is done using linear regression, but on the logarithmic transformations of $\mathrm{M}$ and SQ, BP, DL and TOT. The procedure starts with Eq. 1, $\mathrm{S}$ a $\mathrm{M}^{\mathrm{b}}$, but with SQ, BP, DL and TOT replacing S. Scatterplots of current male world record holders (as of May, 2011, http://records.powerlifting.org/world) for these four events are shown in Fig. 2. Note that the exponent is the unknown, as the purpose of empirical testing is to determine the actual $\mathrm{M}$ exponent for that sample. For purposes of illustrations, TOT will be chosen: TOT a M $\mathrm{M}^{\mathrm{b}}$. This really means that the best-fit curve of a scatterplot of TOT vs. $\mathrm{M}$ will conform to the following equation:

$$
\mathrm{TOT}=\mathrm{aM}^{\mathrm{b}}
$$


where $\mathrm{a}$ and $\mathrm{b}$ are constants. This is an allometric, not linear relationship. For linear regression, the terms must be in the form of $y=m x+b$. A log transformation of both sides, then, yields the following:

$$
\ln \mathrm{TOT}=(\mathrm{b}) \ln \mathrm{M}+\ln (\mathrm{a})
$$

Squat

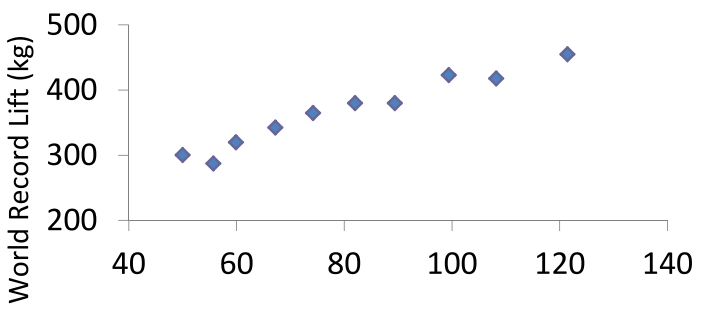

Bench Press

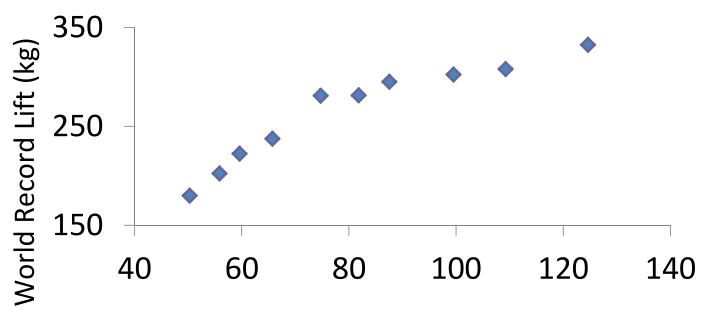

\section{Deadlift}

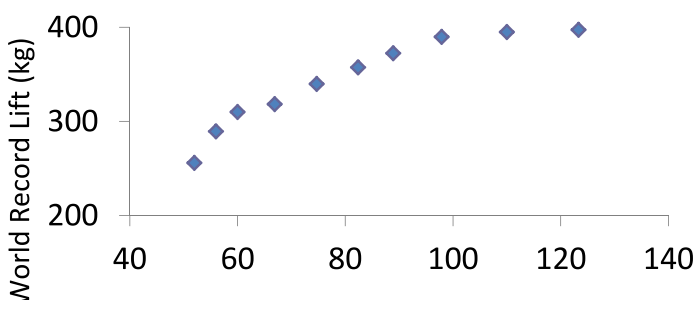

Total

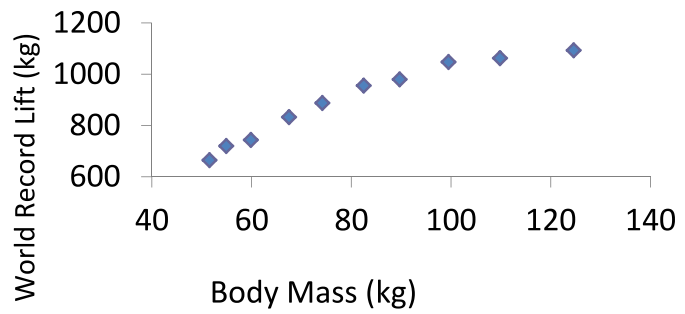

Fig. 2. World powerlifting records by body mass (as of May, 2011, http:/ / records.powerlifting.org/world) 
Now, $\operatorname{lnTOT}$ becomes " $y$," $b$ becomes " $m$," and $\ln (\mathrm{a})$ becomes " $\mathrm{b}$ " in the linear equation. Regressing lnTOT on $\operatorname{lnM}$ will yield not only the value of b but its confidence interval (CI) as well. This is quite important since scatterplots of human performance always deviate from the best-fit curve and CIs give an indication of probability that the population's true exponent lies within it. Linear regression of the log-transformed terms for the TOT event yields an exponent of 0.58 with a $95 \%$ confidence interval of 0.48 to 0.67 . Within this confidence interval (CI), an M exponent would yield zero body mass bias for TOT. Note that $2 / 3$, or 0.667 , is within (but barely) the CI. Table 2 shows the actual body mass exponents for the four different powerlifting events, along with the $95 \%$ CI ranges.

\begin{tabular}{|c|c|c|c|c|}
\cline { 2 - 5 } \multicolumn{1}{c|}{} & SQ & BP & DL & TOT \\
\hline Exponent & 0.50 & 0.65 & 0.48 & 0.58 \\
\hline 95\% CI & $0.42-0.59$ & $0.49-0.80$ & $0.37-0.60$ & $0.48-0.67$ \\
\hline
\end{tabular}

Table 2. Body mass exponents for world record powerlifting performances (Fig.2)

This table illustrates a number of key points in evaluating empirical data for allometric scaling. First, among the world's elite, a small number of subjects ( $\mathrm{N}=10$ in this case) can show the characteristic curvilinear allometric relationship between body mass and performance. Each event indicates, as body mass increases, the expected smaller and smaller increase in performance. Said differently, the relationships are clearly not linear. Second, since neither is in the CI ranges, the exponents of 0 or 1 impose a body mass bias. While an exponent of 0 yielding such bias is expected since that would be analogous to no weight classes, the exponent of 1 doing the same might be surprising. These data show that, in any of the events, dividing the performance by body mass (e.g., SQ/ $\mathrm{M}^{1}$ ) would also yield body mass bias. This actually conforms to the laws of biological scaling since the exponent of 1 is too large. In other words, the index SQ/M makes too much of an adjustment for $\mathrm{M}$, thus penalizing larger competitors.

Third, and perhaps surprisingly, not all the exponents' CIs contain the expected value of $2 / 3$. There are many reasons why this can, and often does happen in allometry research. With a small sample size, one case can influence the magnitude of the exponent. In the TOT, for example, removing the heaviest competitor changes the exponent from 0.58 to 0.63 , the latter for which the $2 / 3$ exponent easily fits within the $95 \% \mathrm{CI}$ range, not barely as with all the competitors. In the case of world record holders, as others have conjectured for world class powerlifting events (Dooman \& Vanderburgh, 2000; Vanderburgh \& Batterham, 1999; Vanderburgh \& Dooman, 2000), there are more competitors worldwide in the middle weight classes and fewer at the extremes. This would suggest that, adjusted for body mass differences, the world's best in the middle weight classes would be better than the best from the lightest and heaviest classes, thus "bumping" up the middle of the curve. This would affect goodnessof-fit with an allometric model and alter the exponent value away from the theoretical. One other worthwhile explanation in the present data is that both the squat and deadlift exercises, unlike the bench press, lift not only the barbells but a substantial percentage of the body mass as well. Since moving body mass is disadvantageous for larger individuals, this would lessen the slope of the best-fit curve for the scatterplots such as those in Fig. 2, the result would be a smaller exponent. Indeed, Table 2 indicates that the smallest exponents are for squat and deadlift. In large samples of non-world-class subjects, there are many other confounders such as body composition, effort, biomechanics, etc. Often, when deviation from theoretical is 
found, researchers are faced with offering reasonable explanations without the statistical control to back such claims. The best research samples, then, are those in which the subjects are heterogeneous in the dependent variable (performance score) and body mass but homogeneous in the potential confounders such as effort and body composition.

Some studies have indicated deviation from theoretical for the body mass exponent for expressing $\mathrm{VO}_{2 \max }$. Batterham et al. (1999) found that, in a sample of 1314 adult men, although the body mass exponent was 0.65 , the fat-free mass exponent was not different from 1.0. Since body fat is essentially metabolically inert, and fat-free mass is the body compartment largely responsible for generating oxygen consumption, then body composition was a confounder in leading to the spurious conclusion that the 0.65 body mass exponent matched the theoretically expected value of 2/3. Similarly, Vanderburgh et al. (1996a), in a sample of 94 adult women, determined that while ratio scaling of $\mathrm{VO}_{2 \max }$ penalized heavier women, the penalty was due to the body fatness.

Another interesting but quite common dilemma is assuming validity when the empirically derived exponent matches the theoretical, as is the case with the BP and TOT events. Indeed, these findings could be the result of confounding effects on the exponent such that the

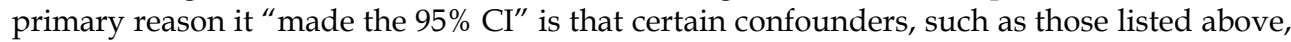
happened to push the exponent value into the theoretical range. In other words, one can never be quite sure how the empirical did or did not match the theoretical.

As is the case with inferential statistics, however, one should always consider the totality of research evidence from multiple samples from different populations using appropriate statistical control to evaluate the overall trend for allometry's effects on human performance. Based on two extensive reviews (Jaric et al., 2005; Vanderburgh, 2008), one can make a compelling case that use of the exponents as described in Table 3 is appropriate for fitness testing, especially for adult men.

\begin{tabular}{|c|c|c|c|c|}
\hline & $\begin{array}{c}\text { PU } \\
\text { (max reps) }\end{array}$ & $\begin{array}{c}\text { SU } \\
\text { (max reps) }\end{array}$ & $\begin{array}{c}\text { BP } \\
\text { (1RM) }\end{array}$ & DR (time) \\
\hline Exponent & PU.M1/3 & SU.M1/3 & $\mathrm{BP} / \mathrm{M}^{2 / 3}$ & $\mathrm{DR} / \mathrm{M}^{1 / 3}$ \\
\hline References & $\begin{array}{l}\text { Crowder \& } \\
\text { Yunker, 2000 } \\
\text { Markovic \& } \\
\text { Jaric, 2004 } \\
\text { Vanderburgh } \\
\text { et al., in press }\end{array}$ & $\begin{array}{l}\text { Markovic \& } \\
\text { Jaric, } 2004\end{array}$ & $\begin{array}{l}\text { Dooman \& } \\
\text { Vanderburgh, } 2000 \\
\text { Markovic \& Jaric, } 2004 \\
\text { Vanderburgh \& } \\
\text { Dooman, 2000 }\end{array}$ & $\begin{array}{l}\text { Crowder \& Yunker, } \\
2000 \\
\text { Nevill et al., } 1992 \\
\text { Vanderburgh \& } \\
\text { Mahar, } 1995 \\
\text { Vanderburgh et al., in } \\
\text { press }\end{array}$ \\
\hline
\end{tabular}

$\mathrm{PU}=$ Pushups, $\mathrm{SU}=$ Situps, $\mathrm{DR}=$ Distance run time

Table 3. Allometric indices for common fitness tests

\section{The utility of allometry in fitness testing}

These indices can be used to compare individual fitness scores among people of varying body weights. The results of some hypothetical examples can be illuminating. Consider two individuals, Ellen and June, with the fitness scores as shown in Table 4. Scaled scores are calculated using the indices from Table 3, maintaining the appropriate units. Clearly, body mass influences scoring with the allometric indices, which make a proper adjustment for its 
influence. One can interpret allometric comparisons as follows, using a Table 4 example: "Without consideration of the influence of body mass on pushups, Ellen performed $11.8 \%$ more repetitions. Considering the influence of body mass, however, June scored $4.6 \%$ better." In the case of the bench press, June's performance was $47.7 \%$ better than Ellen's for raw score but only $8.0 \%$ better when making a proper adjustment for body mass.

On a more significant scale, the effect of body mass bias among military personnel has been quantified (Vanderburgh \& Crowder, 2006). For example, a $90 \mathrm{~kg}$ man performing at the same physiological level as a $60 \mathrm{~kg}$ man who achieved a maximum score on the U.S.

\begin{tabular}{|l|c|c|c|c|}
\cline { 3 - 5 } \multicolumn{2}{c|}{} & Ellen & June & Comparison \\
\hline Body Mass & -- & $50 \mathrm{~kg}$ & $80 \mathrm{~kg}$ & -- \\
\hline \multirow{2}{*}{ Pushups } & Raw & $38 \mathrm{reps}$ & $34 \mathrm{reps}$ & Ellen by $11.8 \%$ \\
\cline { 2 - 5 } & Scaled & $140.0 \mathrm{reps} \cdot \mathrm{M}^{1 / 3}$ & $146.5 \mathrm{reps} \cdot \mathrm{M}^{1 / 3}$ & June by $4.6 \%$ \\
\hline \multirow{2}{*}{$\begin{array}{l}\text { Bench } \\
\text { Press }\end{array}$} & Raw & $44 \mathrm{~kg}$ & $65 \mathrm{~kg}$ & June by $47.7 \%$ \\
\cline { 2 - 5 } & Scaled & $3.24 \mathrm{~kg} \cdot \mathrm{M}^{-0.67}$ & $3.50 \mathrm{~kg} \cdot \mathrm{M}^{-0.67}$ & June by $8.0 \%$ \\
\hline \multirow{2}{*}{ 2-Mile Run } & Raw & $13: 24$ & $15: 00$ & Ellen by $10.7 \%$ \\
\cline { 2 - 5 } & Scaled & $3.64 \mathrm{~min} \cdot \mathrm{M}^{-1 / 3}$ & $3.48 \mathrm{~min} \cdot \mathrm{M}^{-1 / 3}$ & June by $4.4 \%$ \\
\hline
\end{tabular}

Table 4. Hypothetical example of the effects of allometry in fitness testing

Army Physical Fitness Test of pushups, situps, and two-mile run, would actually receive a $15 \%$ lower score (256 vs. 300 points). In this case, "same physiological level" is the expected performance of a $90 \mathrm{~kg}$ man who is an exact scale model of the $60 \mathrm{~kg}$ man. Similarly, for a 45 $\mathrm{kg}$ vs. $75 \mathrm{~kg}$ woman, the U.S. Navy's test levies a $20 \%$ penalty. In the case of the Armed Services, there are actually two very real undesirable consequences for the larger service members. First, advancement and promotion is influenced by the fitness test scores. For the two women above, the heavier who scored physiologically equivalent 240 points compared to the lighter's 300 max points, is at a substantial promotion disadvantage, all other factors being equal. Second, occupational physiology findings suggest that larger military personnel tend to be better performers of physically demanding military tasks (Bilzon et al., 2001; Bilzon et al., 2002, Harman \& Frykman, 1992; Harman et al., 2008; Lyons et al., 2005; Rayson et al., 2000). These include: heavy materiel handling, load carriage, and casualty evacuation - tasks that involve not only moving one's own weight but additional external weight. As a result, and because physical fitness test performance is linked with promotions and advancement within the services, the current physical fitness tests of the U.S. Army, Air Force, and Navy penalize the very populations that perform physically demanding military tasks better.

Body mass bias also occurs in competitive sports, most notably distance running which attracts over two million competitors in race distances of five kilometers or greater each year in the United States. The implications can be substantial. For example, a $68 \mathrm{~kg}$ woman's 50:00 $10 \mathrm{~km}$ race time would be physiologically equivalent to a $50 \mathrm{~kg}$ woman's 45:07 $10 \mathrm{~km}$ time. Accordingly, body weight handicap models for distance runs have been developed and validated to account for body weight differences in determining race performance (Vanderburgh \& Laubach, 2007). Despite the additional credit for larger body mass, these models have also been determined to be disadvantageous for those whose larger mass is due to excess fat mass, an important health-related finding (Vanderburgh et al., in press). 
In some sports, such as wrestling and power lifting, weight classes are the main method of accounting for body weight differences. One of the challenges of such a convention is that there are often few competitors in the extremes of weight and many in the middle weights. This imposes a body weight bias against the middle weight competitors who must compete against many more athletes to win or place. Recent empirical evidence suggests that allometric scaling is a technique that can be used to eliminate all weight classes for each gender and determine the best overall lifter when properly adjusting for body weight differences (Vanderburgh \& Batterham, 1999). In competitive rowing, there are typically only two weight classes for each gender, light and heavy. Vanderburgh et al. (1996) developed and validated an allometric index that allows all rowers of any size within each gender, to be compared to each other while properly factoring out the influence of body mass and age. Their results suggest that rowing time multiplied by stature (or $\mathrm{M}^{1 / 3}$ ) was the optimal index to remove body mass bias among these competitive rowers.

\section{Body fatness and allometry in fitness testing}

One of the main critiques of using allometric scaling in fitness testing is that giving credit for weight in the scoring is to also give credit for excess body fat. In other words, some perceive that such scoring gives advantages for being fatter. Indeed, one's denominator of $\mathrm{M}^{1 / 3}$ for the distance run score computed from the DR/ $\mathrm{M}^{1 / 3}$ calculation would be larger for a fatter individual, thus leading to a lower (and better score, since low score wins). What is not often considered, however, is the effect of the excess fatness on the numerator - in this case, the distance run time. Vanderburgh and colleagues have modeled the effects of adding additional fat weight on the resultant distance run time for the $5 \mathrm{~km}$ and 2-mile runs and have shown that, in all cases, adding fat weight leads to a worse scaled score (Crecilius et al., 2008; Vanderburgh \& Laubach, 2007). Recently, they tested this empirically, by adding external weight to the DR and PU events for college-age men. Results indicated that the addition of $16 \mathrm{~kg}$ of external weight led to $38 \%$ worse scaled PU scores and $12 \%$ worse twomile run scaled scores (Vanderburgh et al., in press).

\section{Practical techniques for using allometry in fitness testing}

As shown in Table 4, allometrically scaled scores yield strange units and currency. That is, one may find the interpretation of a scaled score for a $65 \mathrm{~kg}$ bench press, $3.50 \mathrm{~kg} \cdot \mathrm{M}^{-0.67}$, quite difficult to interpret. This is likely due to the units, $\mathrm{kg} \cdot \mathrm{M}^{-0.67}$, being unlike those encountered elsewhere and the magnitude of 3.50 not being as readily evaluated as $65 \mathrm{~kg}$ would be. Another problem with these scores is that they require a calculator to compute. In short, though arguably proper and fair, allometrically scaled scores are not practical.

Other solutions have been proposed. The first, correction factors, are dimensionless numbers based on body weight, which are multiplied by the raw score to produce an adjusted in the same units and more easily interpretable (Vanderburgh, 2007). For example, from Table 4, Ellen's and June's correction factors would, for PU, be: 1.0 and 1.17, respectively. This is calculated based on a body mass standard - a baseline from which all ratios are computed, the individual's body mass, and the particular event. For a standard weight of $50 \mathrm{~kg}$, for example, and June's body mass of $80 \mathrm{~kg}$, and the PU, her correction factor would be ( $80 \mathrm{~kg} / 50 \mathrm{~kg})^{1 / 3}$, or $1.170^{\prime \prime}$ (in both cases). Multiplying her raw score of 34 pushups by 1.211 yields an adjusted score of 39.78 pushups. Using the same methodology, 
Ellen's adjusted score would be $38 \times 1.0=39.4$ pushups and June's adjusted performance is exactly the same $4.6 \%$ better than Ellen using the correction factors.

Simple tables can be constructed to determine correction factors without calculators and the multiplication of raw score by correction factor can be done with pencil-and-paper. Table 5 illustrates an example from Vanderburgh (2007), applied to the distance run events of United States armed forces fitness tests. In this case, the weight standards were selected as $120 \mathrm{lbs}$. and $150 \mathrm{lbs}$. for women and men, respectively. These values were specifically chosen to allow no credit below these body weights. Though the selection of the standard is arbitrary, it must be used consistently once chosen. Also, correction factors can be less than one as well. Nonetheless, correction factors still impose a logistical challenge in developing tables for each event and their use is not intuitively obvious to users with very little exercise science background.

\begin{tabular}{|l|l|l|l|l|l|l|l|l|l|}
\hline Women & 120 & 130 & 140 & 150 & 160 & 170 & 180 & 190 & 200 \\
\hline 0 & 1.00 & 0.99 & 0.96 & 0.94 & 0.92 & 0.90 & 0.89 & 0.87 & 0.85 \\
\hline 1 & 1.00 & 0.98 & 0.96 & 0.94 & 0.92 & 0.90 & 0.88 & 0.87 & 0.85 \\
\hline 2 & 1.00 & 0.98 & 0.96 & 0.94 & 0.92 & 0.90 & 0.88 & 0.87 & 0.85 \\
\hline 3 & 1.00 & 0.98 & 0.96 & 0.93 & 0.92 & 0.90 & 0.88 & 0.87 & 0.85 \\
\hline 4 & 1.00 & 0.98 & 0.95 & 0.93 & 0.91 & 0.90 & 0.88 & 0.86 & 0.85 \\
\hline 5 & 1.00 & 0.97 & 0.95 & 0.93 & 0.91 & 0.89 & 0.88 & 0.86 & 0.85 \\
\hline 6 & 1.00 & 0.97 & 0.95 & 0.93 & 0.91 & 0.89 & 0.88 & 0.86 & 0.85 \\
\hline 7 & 0.99 & 0.97 & 0.95 & 0.93 & 0.91 & 0.89 & 0.87 & 0.86 & 0.85 \\
\hline 8 & 0.99 & 0.97 & 0.95 & 0.92 & 0.91 & 0.89 & 0.87 & 0.86 & 0.84 \\
\hline 9 & 0.99 & 0.97 & 0.94 & 0.92 & 0.90 & 0.89 & 0.87 & 0.86 & 0.84 \\
\hline
\end{tabular}

\begin{tabular}{|l|l|l|l|l|l|l|l|l|l|l|l|}
\hline Men & 150 & 160 & 170 & 180 & 190 & 200 & 210 & 220 & 230 & 240 & 250 \\
\hline 0 & 1.00 & 0.98 & 0.96 & 0.94 & 0.92 & 0.91 & 0.89 & 0.88 & 0.87 & 0.85 & 0.84 \\
\hline 1 & 1.00 & 0.98 & 0.96 & 0.94 & 0.92 & 0.91 & 0.89 & 0.88 & 0.87 & 0.85 & 0.84 \\
\hline 2 & 1.00 & 0.97 & 0.96 & 0.94 & 0.92 & 0.91 & 0.89 & 0.88 & 0.86 & 0.85 & 0.84 \\
\hline 3 & 0.99 & 0.97 & 0.95 & 0.94 & 0.92 & 0.90 & 0.89 & 0.88 & 0.86 & 0.85 & 0.84 \\
\hline 4 & 0.99 & 0.97 & 0.95 & 0.93 & 0.92 & 0.90 & 0.89 & 0.87 & 0.86 & 0.85 & 0.84 \\
\hline 5 & 0.99 & 0.97 & 0.95 & 0.93 & 0.92 & 0.90 & 0.89 & 0.87 & 0.86 & 0.85 & 0.84 \\
\hline 6 & 0.99 & 0.97 & 0.95 & 0.93 & 0.91 & 0.90 & 0.89 & 0.87 & 0.86 & 0.85 & 0.84 \\
\hline 7 & 0.98 & 0.96 & 0.95 & 0.93 & 0.91 & 0.90 & 0.88 & 0.87 & 0.86 & 0.85 & 0.84 \\
\hline 8 & 0.98 & 0.96 & 0.94 & 0.93 & 0.91 & 0.90 & 0.88 & 0.87 & 0.86 & 0.85 & 0.83 \\
\hline 9 & 0.98 & 0.96 & 0.94 & 0.93 & 0.91 & 0.90 & 0.88 & 0.87 & 0.86 & 0.84 & 0.83 \\
\hline
\end{tabular}

Table 5. Correction Factors for Distance Runs, Pushups, or Situps Tests. A $186 \mathrm{lb}$ man with an actual score two-mile run time of 15:05, for example, would go to the "180" column and down to the row corresponding to " 6 " to yield the correction factor of 0.93 . Since low score wins, this number would be multiplied by the actual time of $905 \mathrm{sec}$ to yield an adjusted score of $841.7 \mathrm{sec}$ or 14:02. For a $172 \mathrm{lb}$ woman with 32 pushups, and high score wins, one would divide her raw score by the 0.90 correction factor to yield an adjusted score of 35.6 pushups (from Vanderburgh, 2007). 
A third solution is the use of a balanced fitness test - one that imposes no body mass advantage. They can be single or multi-event. A backpack run is an example of a singleevent balanced test, in which neither larger nor smaller personnel are disadvantaged. This test, which would require all military personnel to run a given distance with a standardweight backpack, has been mathematically modeled and shown to eliminate body mass bias in men (Vanderburgh \& Flanagan, 2000). This has occupational relevance since the standard backpack load for service members is typically the same, regardless of one's body mass. $\mathrm{He} /$ she must carry that load often over some considerable distance in arduous terrain. The advantage to the larger body mass of the standard weight for everyone is counterbalanced by the disadvantage of moving one's body mass. This backpack run test, along with a backpack pushups test, using the same standard weight of $16 \mathrm{~kg}$, has been validated for college-age men as being free of body mass bias (Vanderburgh, in press). These types of tests, then, require no special calculations and produce raw scores that are fair and occupationally relevant. They do, however, pose a mass testing challenge in terms of the extra equipment needed.

One multi-event test that purports to be balanced is the popular "Pump \& Run,"which entails a distance run and bench press event. One's final score is equal to the distance run time (in sec) minus $30 \mathrm{sec}$ times each repetition of the bench press. The weight lifted, however, is based on a percentage of one's body mass. As Vanderburgh \& Laubach (2008) determined empirically for 74 female and 343 male competitors of one event, the body mass bias against larger competitors was substantial, largely because both events imposed the penalty. The bench press was actually analogous to the pushup exercise which also lifts a percentage of one's weight. The researchers proposed a correction factor table but also recommended the study of a standard weight lifted for all competitors, not one based on body mass. This case study is probably the best single example of the non-intuitive nature of body mass bias; race officials were trying to level the playing field with the two events but the result had just as much body mass bias as the distance run alone.

\section{Conclusion}

Body mass bias is a real phenomenon in fitness testing which is based on the fundamental notion that the ability to move one's weight is not directly proportional to one's body mass. This bias, especially in large-scale testing such as the military, leads to not only an advantage for smaller service members, but a disadvantage against those who perform the physically demanding occupational tasks of the military better - the larger service members. Allometric scaling and its derivative technique of correction factors can be used to erase such biases but, while these are mathematically appropriate and valid, they impose logistical and non-intuitive challenges. Such scoring is also useful in determining the best overall performer in sports such as distance running, powerlifting, and even indoor rowing. Evidence suggests that, although allometric scaling grants a credit for being heavier, if the increased body mass is fat mass, then the resulting scaled score is worse. This is because the detriment in raw score performance is of greater magnitude than the credit granted. Balanced fitness tests like the backpack run and pushups tests, which impose no body mass bias, have been shown to be intuitive, useful and occupationally relevant but are not without their mass testing challenges with regard to equipment needed. Most importantly, exercise scientists who can exercise some level of fluency in the principles of biological scaling and allometry as they apply to fitness testing 
will be able to best interpret human performance scores not only sport, but in occupational fitness and health-related fitness as well.

\section{Acknowledgment}

I would like to acknowledge the following:

- My colleagues at the United States Military Academy at West Point, also my alma mater, where physical fitness is highly valued and excellence is a habit; your energy and passion were contagious.

- The many soldiers and USMA/ROTC cadets of the United States Army who served as subjects in our research; your compliance and cooperation were top-shelf in every way and your efforts were always maximal, a necessary condition for this type of research.

- My colleagues in the field of exercise physiology, especially Dr. Todd Crowder, Dr. Alan Batterham, Dr. Lloyd Laubach, and Dr. Tom Rowland; your friendship, enthusiasm, and collegiality were not only the key ingredients for productivity but for having fun along the way.

- $\quad$ The graduate students with whom I've had the pleasure to work; I hope you learned as much from our collaborations as I did.

\section{References}

Astrand, P. \& Rodahl, K. (1986). Textbook of Work Physiology. McGraw Hill ISBN 0-7360-01409, New York, pp.399-405,

Batterham, A.; Vanderburgh, P.; Mahar, M. \& Jackson, A. (1999). Modeling the influence of body size on $\mathrm{VO}_{2 \text { peak: }}$ Effects of model choice and body composition. Journal of Applied Physiology, Vol.87, No.4, pp. 1317-1325, ISSN 8750-7587

Bilzon, J.; Allsopp, A. \& Tipton, M. (2001). Assessment of physical fitness for occupations encompassing load-carriage tasks. Occupational Medicine. Vol.51, No.5, pp. 357-361, ISSN 0962-7480

Bilzon, J; Scarpello, E.; Bilzon, E. \& Allsop, A. (2002) Generic task-related occupational requirements for Royal Navy personnel. Occupational Medicine, Vol.52, No.8, pp. 503510, ISSN 0962-7480

Crecelius, A.; Vanderburgh, P. \& Laubach, L. (2008). Contributions of body fat and effort in the $5 \mathrm{~K}$ run age and body weight handicap model. Journal of Strength and Conditioning, Vol.22, No.5, pp. 1475-1480, ISSN 1064-8011

Crowder, T. \& Yunker, C. (1986). Scaling of push-up, sit-up and two-mile run performances by body weight and fat-free weight in young, fit men [Abstract]. Medicine and Science in Sports and Exercise, Vol.28, No.5, p.S183, ISSN 0195-9131

Dooman C. \& Vanderburgh, P. (2000). Allometric modeling of the bench press and squat: Who is the strongest regardless of body mass? Journal of Strength and Conditioning Research, Vol.14, No.1, pp. 32-36, ISSN 1064-8011

Harman, E. \& Frykman, P. (1992). The relationship of body size and composition to the performance of physically demanding military tasks. In: Body Composition and Physical Performance. National Academy Press ISBN 0-309-0458, pp.105-18

Harman, E.; Gutekunst, D.; Frykman, P.; Sharp, M.; Nindl, B.; Alemany, J. \& Mello, R. (2008). Prediction of Simulated Battlefield Physical Performance from FieldExpedient Tests. Military Medicine, Vol.173, No.1, pp.36-41, ISSN 0026-4075 
Heil, D. (1997). Body mass scaling of peak oxygen uptake in 20- to 79-yr-old adults. Medicine and Science in Sports and Exercise, Vol.29, No.12, pp.1602-1608, ISSN 0195-9131

Jaric, S. (2002). Muscle strength testing - Use of normalization for body size. Sports Medicine, Vol.32, No.10, pp. 615-631, ISSN 0112-1642

Jaric, S.; Ugarkovic, D. \& Kukolj, M. (2002). Evaluation of methods of normalizing muscle strength in elite and young athletes. Journal of Sports Medicine and Physical Fitness, Vol.42, No.2, pp. 141-151, ISSN 0022-4707

Jaric, S.; Radosavljevic-Jaric, S. \& Johansson, H. (2002). Muscle force and muscle torque in humans require different methods when adjusting for differences in body size. European Journal of Applied Physiology, Vol.87, No. 3, pp. 304-7, ISSN 1439-6319

Jaric, S.; Mirkov, D. \& Markovic, G. (2005). Normalizing physical performance tests for body size: A proposal for standardization. Journal of Strength and Conditioning Research, Vol.19, No.2, pp.467-74, ISSN 1064-8011

Lyons, J.; Allsopp, A. \& Bilzon, J. (2005). Influences of body composition upon the relative metabolic and cardiovascular demands of load-carriage. Occupational Medicine, Vol.55, No.5., pp. 380-384, ISSN 0962-7480

Markovic, G. \& Jaric, S. (2004). Movement performance and body size: The relationship for different groups of tests. European Journal of Applied Physiology, Vol.92, No.1, pp. 139-149, ISSN 1439-6319

Nevill, A.; Ramsbottom, R. \& Williams, C. (1992). Scaling physiological measurements for individuals of different body size. European Journal of Applied Physiology, Vol.65, No.2, pp. 110-17, ISSN 1439-6319

Rayson, M; Holliman, D. \& Belyavin, A. (2000). Development of physical selection procedures for the British Army. Phase 2: Relationship between physical performance tests and criterion tasks. Ergonomics, Vol.43, No.1, pp. 73-105, ISSN 0014-0139

Vanderburgh, P.; Mahar, M. \& Chou, C. (1995). Allometric scaling of grip strength by body mass in college-age men and women. Research Quarterly for Exercise and Sport, Vol.66, No.1, pp.80-84, ISSN 0270-1367

Vanderburgh, P., \& Mahar, M. (1995). Scaling of 2-mile run times by body weight and fatfree weight in college-age men. Journal of Strength and Conditioning Research, Vol.9, No.2, pp. 67-70, ISSN 1064-8011

Vanderburgh, P. \& Katch, F. (1996). Ratio scaling of $\mathrm{VO}_{2 \max }$ penalizes women with larger percent body fat, not lean body mass. Medicine and Science in Sports and Exercise, Vol.28, No.9, pp. 1204-8, ISSN 0195-9131

Vanderburgh, P.; Katch, F; Schoenleber, J.; Balabinis, C. \& Elliott, R. (1996). Multivariate allometric scaling of men's world indoor rowing championship performance. Medicine and Science in Sports and Exercise, Vol.28, No.5, pp. 626-30, ISSN 0195-9131

Vanderburgh, P. (1998). Two important cautions in the use of allometric scaling: The common exponent and group differences principles. Measurement in Physical Education and Exercise Science, Vol.2, No.3, pp. 153-63, ISSN 1091-367X

Vanderburgh, P. \& Batterham, A. (1999). Validation of the Wilks Powerlifting formula. Medicine and Science in Sports and Exercise, Vol.31, No.12, pp. 1869-75, ISSN 01959131 
Vanderburgh, P. \& Dooman C. (2000). Considering body mass differences, who are the world's strongest women? Medicine and Science in Sports and Exercise, Vol.32, No.1, pp. 197-201, ISSN 0195-9131

Vanderburgh, P. \& Flanagan, S. (2000). The Backpack Run Test: A model for a fair and occupationally relevant military fitness test. Military Medicine, Vol.165, No.5, pp.418-21, ISSN 0026-4075

Vanderburgh, P. \& Crowder, T. (2006). Body weight penalties in the physical fitness tests of the Army, Air Force, and Navy. Military Medicine, Vol.171, No.8, pp. 753-756, ISSN 0026-4075

Vanderburgh, P. \& Laubach, L. (2007). Derivation of an age and weight handicap for the $5 \mathrm{~K}$ run. Measurement in Physical Education and Exercise Science, Vol.11, No.1, pp. 49-59, ISSN ISSN 1091-367X

Vanderburgh, P. (2007). Correction factors for body mass bias in military physical fitness tests. Military Medicine, Vol.172, No.7, pp. 738-742, ISSN 0026-4075

Vanderburgh, P. \& Laubach, L. (2008). Body mass bias in a competition of muscle strength and aerobic power. Journal of Strength and Conditioning Research, Vol.22, No.2, pp. 375-382, ISSN 1064-8011

Vanderburgh, P. (2008). Occupational relevance and body mass bias of in military physical fitness tests. Medicine and Science in Sports and Exercise, Vol.40, No.8, pp. 1538-1545, ISSN 0195-9131

Vanderburgh, P.; Mickley, N.; Anloague, P. \& Lucius K. Load carriage distance run and pushups tests: No body mass bias and occupationally relevant. Military Medicine, (in press), ISSN 0026-4075 


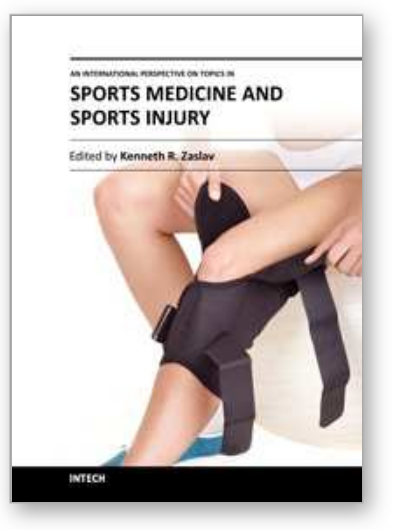

\author{
An International Perspective on Topics in Sports Medicine and \\ Sports Injury \\ Edited by Dr. Kenneth R. Zaslav
}

ISBN 978-953-51-0005-8

Hard cover, 534 pages

Publisher InTech

Published online 17, February, 2012

Published in print edition February, 2012

For the past two decades, Sports Medicine has been a burgeoning science in the USA and Western Europe. Great strides have been made in understanding the basic physiology of exercise, energy consumption and the mechanisms of sports injury. Additionally, through advances in minimally invasive surgical treatment and physical rehabilitation, athletes have been returning to sports quicker and at higher levels after injury. This book contains new information from basic scientists on the physiology of exercise and sports performance, updates on medical diseases treated in athletes and excellent summaries of treatment options for common sports-related injuries to the skeletal system.

\title{
How to reference
}

In order to correctly reference this scholarly work, feel free to copy and paste the following:

Paul M. Vanderburgh (2012). Body Mass Bias in Exercise Physiology, An International Perspective on Topics in Sports Medicine and Sports Injury, Dr. Kenneth R. Zaslav (Ed.), ISBN: 978-953-51-0005-8, InTech, Available from: http://www.intechopen.com/books/an-international-perspective-on-topics-in-sports-medicineand-sports-injury/body-mass-bias-in-exercise-physiology

\section{INTECH}

open science | open minds

\section{InTech Europe}

University Campus STeP Ri Slavka Krautzeka 83/A 51000 Rijeka, Croatia Phone: +385 (51) 770447

Fax: +385 (51) 686166 www.intechopen.com

\section{InTech China}

Unit 405, Office Block, Hotel Equatorial Shanghai No.65, Yan An Road (West), Shanghai, 200040, China 中国上海市延安西路65号上海国际贵都大饭店办公楼405单元 Phone: +86-21-62489820

Fax: +86-21-62489821 
(C) 2012 The Author(s). Licensee IntechOpen. This is an open access article distributed under the terms of the Creative Commons Attribution 3.0 License, which permits unrestricted use, distribution, and reproduction in any medium, provided the original work is properly cited. 